\title{
Trackline and point detection probabilities for acoustic surveys of Cuvier's and Blainville's beaked whales
}

\author{
Jay Barlow ${ }^{\mathrm{a})}$ \\ Protected Resources Division, Southwest Fisheries Science Center, National Oceanic and Atmospheric \\ Administration, National Marine Fisheries Service, 8901 La Jolla Shores Drive, La Jolla, California 92037 \\ Peter L. Tyack and Mark P. Johnson \\ Scottish Oceans Institute, East Sands, St. Andrews, Fife, Scotland KY15 5NT, United Kingdom
}

Robin W. Baird and Gregory S. Schorr

Cascadia Research Collective, 218 [1/2] West 4th Avenue, Olympia, Washington 98501

Russel D. Andrews

School of Fisheries and Ocean Sciences, University of Alaska Fairbanks, and Alaska SeaLife Center, 301 Railway Avenue, Seward, Alaska 99664

Natacha Aguilar de Soto

BIOECOMAC, Department of Animal Biology, University of La Laguna, Tenerife, Canary Islands, Spain

(Received 9 November 2012; revised 18 January 2013; accepted 21 February 2013)

\begin{abstract}
Acoustic survey methods can be used to estimate density and abundance using sounds produced by cetaceans and detected using hydrophones if the probability of detection can be estimated. For passive acoustic surveys, probability of detection at zero horizontal distance from a sensor, commonly called $g(0)$, depends on the temporal patterns of vocalizations. Methods to estimate $g(0)$ are developed based on the assumption that a beaked whale will be detected if it is producing regular echolocation clicks directly under or above a hydrophone. Data from acoustic recording tags placed on two species of beaked whales (Cuvier's beaked whale-Ziphius cavirostris and Blainville's beaked whaleMesoplodon densirostris) are used to directly estimate the percentage of time they produce echolocation clicks. A model of vocal behavior for these species as a function of their diving behavior is applied to other types of dive data (from time-depth recorders and time-depth-transmitting satellite tags) to indirectly determine $g(0)$ in other locations for low ambient noise conditions. Estimates of $g(0)$ for a single instant in time are 0.28 [standard deviation (s.d.) $=0.05$ ] for Cuvier's beaked whale and 0.19 (s.d. = 0.01) for Blainville's beaked whale. [http://dx.doi.org/10.1121/1.4816573]
\end{abstract}

PACS number(s): 43.80.Ka [AMT]

Pages: 2486-2496

\section{INTRODUCTION}

Beaked whales (family Ziphiidae) are a poorly known group of 21 recognized cetacean species found almost exclusively in deep oceanic waters. Although several species are found in groups of tens of individuals, most have characteristic group sizes of less than five and solitary individuals are commonly seen. Most species also surface without conspicuous visual cues such as blows or splashes. Their offshore habitat, small group sizes, and cryptic surface behavior make beaked whale studies difficult. Consequently, little is known about the abundance or population density of beaked whales (Barlow et al. 2006) and major gaps exist in knowledge of their distributions (MacLeod et al. 2006).

Recent work has characterized echolocation signals of several beaked whale species and has shown that these signals are species-specific (Dawson et al., 1998; Hooker and Whitehead, 2002; Johnson et al., 2004; Madsen et al., 2005; Zimmer et al., 2005; Johnson et al., 2006, 2008; Gillespie et al., 2009; Baumann-Pickering et al., 2010). Behavioral

\footnotetext{
a) Author to whom correspondence should be addressed. Electronic mail: Jay.Barlow@noaa.gov
}

studies using acoustic recording tags attached to beaked whales with suction cups have revealed that two beaked whale species (Cuvier's beaked whale-Ziphius cavirostris and Blainville's beaked whale-Mesoplodon densirostris) produce echolocation clicks almost continuously when foraging and seldom echolocate or produce communication sounds when they are not foraging (Tyack et al. 2006, Aguilar de Soto et al., 2012).

Given that some beaked whale species may be recognizable from their echolocation clicks and that their clicks are produced regularly and predictably, passive acoustic survey methods (Marques et al., 2013) may be a valuable tool for studies of beaked whale density and abundance. Acoustic surveys are especially attractive for beaked whales given the difficulty in estimating their abundance by visual survey methods (Barlow et al., 2006). Three previous studies estimated the density of Blainville's beaked whale in the Tongue of the Ocean, Bahamas using a dense array of bottom-mounted hydrophones (Moretti et al., 2006; Marques et al., 2009; Moretti et al., 2010). Ward et al. (2012) used the same high-density array to estimate the abundance of sperm whales. Although the methods developed in those papers demonstrate feasibility, they are not applicable to 
wider areas of the world's oceans that do not have dense hydrophone arrays. The development of distance sampling methods (Buckland et al., 2001) using either towed hydrophones (Barlow and Taylor, 2005) or individual fixed hydrophones (Küsel et al., 2011) is needed to expand the use of passive acoustic surveys for beaked whales.

Distance sampling methods for density estimation require that the probability of detecting an individual animal or group of animals in the immediate vicinity of a survey platform is known or can be estimated (Buckland et al., 2001). The decline in detection probability with increasing distance can then be estimated from empirical data collected on a survey (i.e., the observed detection distances), which allows density to be estimated based on a much larger sample of detections than would be possible if detections were limited to the immediate vicinity of the survey platform. For passive acoustic surveys, the survey platform can be a ship towing a hydrophone array (a line-transect survey) or an autonomous recording system with a hydrophone array anchored to the bottom (a point-transect survey). A drifting hydrophone array can also be treated as a point-transect survey if the drift speed is much slower than the speed of animal movement. In either case, an array of hydrophones is typically needed to estimate detection distances using one of several localization techniques for passive acoustic monitoring (Zimmer, 2011). Distance sampling methods also exist that are based on detecting "cues," such as individual echolocation clicks (Marques et al., 2009) instead of detecting individual animals or groups of animals; these cue-counting methods will not be specifically addressed in this paper.

For group-based distance sampling methods, one of the key parameters is the probability of detecting a group of animals that is in the immediate vicinity of a hydrophone. Here, for simplicity, we use the term "group" to include either groups of whales or solitary individuals. For acoustic surveys of beaked whales, this value cannot be assumed to be 1.0 (certain detection) because beaked whales are silent for long periods of time (Tyack et al., 2006). In distancesampling terminology, $g(x)$ represents the probability of detecting a group at a horizontal distance $x$ from the transect line (for line-transect surveys) or from the location of the autonomous recording hydrophones (for point-transect surveys). Because density is measured in animals per unit of surface area, distances $x$ are measured from a line or point on the surface of the globe to the projection of the animals' location onto the globe and thus does not include a depth component. In this paper, we estimate $g(0)$ or the probability of detecting beaked whales at zero horizontal distance. This probability depends jointly on the probability that a group of whales will be producing echolocation clicks and the probability that clicks will be detected if produced.

Recent technological advancements allow direct measurements of the acoustic behavior of Cuvier's and Blainville's beaked whales using acoustic recording tags attached by suction cups (Johnson et al., 2004; Tyack et al., 2006). These studies have shown that the diving and acoustic behavior of both species is similar, but with some important differences. Both species commonly produce echolocation clicks only during deep and long dives, which we will term "foraging dives" (Johnson et al., 2004; Madsen et al., 2005). During a foraging dive, they begin clicking only when they have reached a depth of several hundred meters and quit producing clicks long before they return to the surface (Tyack et al., 2006; Arranz et al., 2011). The total time spent clicking (i.e., actively foraging) is much less than the total time of foraging dives (Fig. 2 in Tyack et al., 2006). Foraging dives in these studies were typically followed by several shorter, shallower dives. A similar pattern of long dives followed by a series of shorter, shallower dives has also been seen using other types of tags that do not record acoustic data (Baird et al., 2006). Characteristic dive profiles and clicking behaviors for both species are shown in Fig. 1.

For these two species, we use data from acoustic recording tags to estimate the probabilities that a group will be producing echolocation clicks. We also use these tag data to model the acoustic behavior of these beaked whales based on dive depth and duration. We apply this model to data from other types of tags that record depth and time but do not record acoustic data. We show that both types of tags show very similar patterns, and we pool tagging data from a variety of locations around the globe. Using data from both types of tags, we estimate the probability that the whales will be clicking at any instant in time, and from this we estimate acoustic $g(0)$ for line- and point-transect surveys for Cuvier's and Blainville's beaked whales.

\section{METHODS}

\section{A. Field data collection}

The probability of acoustically detecting beaked whales is clearly dependent on the fraction of time they are producing echolocation clicks. The time spent clicking and the patterns of clicking and non-clicking periods were measured directly using acoustic recording tags that were attached to the animal with suction cups using a long pole (DTAGsJohnson and Tyack, 2003). These tags digitally record 16-bit acoustic data to flash memory at $96-$ or $192-\mathrm{kHz}$ sampling rates, typically for several hours. DTAGs also record pressure (depth) at a $50-\mathrm{Hz}$ sampling rate. DTAGs were placed on Cuvier's beaked whales in the Ligurian Sea, Italy (Johnson et al., 2004) and on Blainville's beaked whales in the Canary Islands (Johnson et al., 2004, Aguilar de Soto
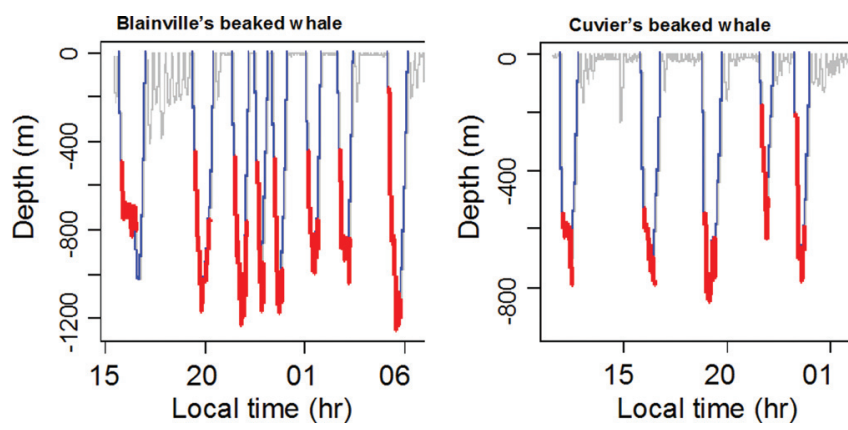

FIG. 1. Typical dive profiles for Blainville's beaked whale (left, individual \#MdH1) and Cuvier's beaked whale (right, tag number zc03_263a) tagged with DTAGs. Blue segments indicate foraging dives and red segments indicate periods of echolocations clicks. Light gray segments indicate nonforaging dives. 
et al., 2012) and in the Bahamas (Tyack et al., 2011). These tags were recovered with the aid of internal VHF transmitters, and data were downloaded and stored for later analysis. We did not use DTAG data that were collected during acoustic playback experiments (also known as behavioral response studies) because of the potential for behavioral changes in response to those sounds (Tyack et al., 2011). Because tagging itself may also affect normal diving and acoustic behavior, we tested whether the duration of the first foraging dive and the first inter-dive interval (the time between the first and second foraging dives) after tagging were significantly different than those of subsequent foraging dives, and we excluded the first foraging dives if either duration or interval were significantly different.

DTAG data show that acoustic behavior is so tightly tied to diving behavior that acoustic behavior could be accurately predicted from diving behavior alone (see Sec. III). Consequently, we expanded our geographic coverage and increased sample size by including studies that used tags that only recorded diving behavior. Time-depth recorders (Wildlife Computers Mk8 and Mk9 TDRs) were attached by suction cups to Cuvier's and Blainville's beaked whales off Hawaii using either a crossbow or pole deployment method (Baird et al., 2006, 2008). TDR tags remained attached for a range of times from hours to days. They were recovered with the aid of VHF transmitters, and data were downloaded and stored for later analysis. Satellite-linked time-depth recorders (SLTDRs) (Wildlife Computers Mk10-A tags in the LIMPET configuration) were deployed from an air rifle (Andrews et al., 2008) and attached with barbed darts on Cuvier's beaked whales off Hawaii and Southern California (Schorr et al., 2011). Summary data including durations of each dive and surfacing series and maximum depth of each dive were transmitted via satellite. Not all dive or surfacing series were represented in SLTDR data due to limited satellite overpasses, but much longer tag durations (averaging approximately six weeks) were achieved with SLTDR tags.

For all tag data, we use only complete cycles of a foraging dive and the subsequent inter-dive interval before the next foraging dive (in the sense of Arranz et al., 2011). If a tag fell off or if SLTDR data were truncated during a foraging dive or during the subsequent inter-dive interval, we excluded both time periods from our analysis.

\section{B. Statistical analyses of dive data}

Multivariate analysis of variance (ANOVA) was used to determine factors that affect the duration of dives and interdive periods for foraging dives. Factors considered in this analysis include location (Table I), tag type (Table I), time of day (day or night as categories), and individual (repeated measure from the same tag deployment).

\section{Estimation of detection probability}

The probability of acoustically detecting beaked whales at zero horizontal distance, $g(0)$, is dependent on both the probability that the whales will be making sounds (echolocation clicks) and on the probability of detecting these sounds if they are made. In this paper, we make the simplifying assumption that vocalizing beaked whales will be detected with certainty if they are directly under a towed or floating hydrophone or directly over a bottom-mounted hydrophone. Based on sonar equations, Zimmer et al. (2008) estimated that an individual echolocation click for a beaked whale would be detected with near certainty out to a horizontal range of $\sim 700 \mathrm{~m}$ in low ambient noise conditions and that the detection probability would drop to near zero at a horizontal range of $\sim 4000 \mathrm{~m}$ (for a click produced at a depth of $720 \mathrm{~m}$ and a receiver at $100 \mathrm{~m}$ ). Marques et al. (2009) used an empirical approach with bottom-mounted hydrophones at $\sim 2000 \mathrm{~m}$ depth and also found that a click could be detected with near certainty at zero horizontal distance if the receiver is centered on the axis of the focused beam, but that study found a greater maximum detection range of $\sim 6000 \mathrm{~m}$ (again, for on-axis clicks in quiet ocean conditions). For off-axis clicks, Marques et al. (2009, their Fig. 3) found that detection probability of a single click drops to 0.4-0.6 at zero horizontal distance. Beaked whales produce approximately 2-10 clicks per second (Baumann-Pickering et al., 2010) and frequently change their orientation to scan for potential prey items (Johnson et al., 2008). Consequently, if the probability of detecting a single click is high at zero horizontal distance, then we feel confident that the probability of

TABLE I. Summary results for tagging studies of beaked whale diving behavior, stratified by species, location, and type of tag. Foraging dives were identified based on presence of regular echolocation clicks (for DTAG data with acoustic recordings) or based on a (dive depth $\times$ dive time) criteria if acoustic data were not available. Mean values are the average of the means for each individual. Standard errors of these means (in parentheses) are not available (N/A) if the number of tag deployments is less than 3.

\begin{tabular}{|c|c|c|c|c|c|c|c|}
\hline Species & Location & Tag type & $\begin{array}{c}\text { \# Tag } \\
\text { deployments }\end{array}$ & $\begin{array}{l}\text { \# Foraging } \\
\text { dives }\end{array}$ & $\begin{array}{l}\text { Mean foraging } \\
\text { dive time (min) }\end{array}$ & $\begin{array}{l}\text { Mean time between } \\
\text { foraging dives (min) }\end{array}$ & $\begin{array}{c}\text { Maximum foraging } \\
\text { dive depth }(\mathrm{m})\end{array}$ \\
\hline \multirow[t]{4}{*}{$\begin{array}{l}\text { Blainville's } \\
\text { beaked whale }\end{array}$} & Canary Islands & DTAG & 13 & 57 & $46.6(1.4)$ & $87.5(12.5)$ & $783(34)$ \\
\hline & Bahamas & DTAG & 3 & 20 & $52.3(1.9)$ & $103.4(10.8)$ & $1023(95)$ \\
\hline & Hawaii & TDR & 8 & 103 & $49.8(2.3)$ & $103.3(9.6)$ & $1068(53)$ \\
\hline & All areas pooled & All & 24 & 180 & $48.9(1.2)$ & $96.8(6.7)$ & $942(44)$ \\
\hline \multirow[t]{5}{*}{ Cuvier's beaked whale } & Ligurian Sea & DTAG & 11 & 44 & $53.7(3.7)$ & $43.1(7.4)$ & $1076(135)$ \\
\hline & Hawaii & TDR & 2 & 17 & $66.2(\mathrm{~N} / \mathrm{A})$ & 85.5 (N/A) & 1273 (N/A) \\
\hline & Hawaii & SLTDR & 1 & 32 & 58.7 (N/A) & $60.2(\mathrm{~N} / \mathrm{A})$ & 1308 (N/A) \\
\hline & Southern California & SLTDR & 2 & 323 & $67.0(\mathrm{~N} / \mathrm{A})$ & $107.1(\mathrm{~N} / \mathrm{A})$ & 1445 (N/A) \\
\hline & All areas pooled & All & 16 & 416 & $59.4(3.2)$ & $66.1(10.3)$ & $1212(81)$ \\
\hline
\end{tabular}


detecting a group of beaked whales over a finite time period (say, 1 min) must be near certainty given that each individual is making multiple clicks every second. Making this assumption that foraging beaked whales will be detected with certainty at zero horizontal distance, the estimation of $g(0)$ focuses on estimating the probability that a beaked whale will be producing echolocation clicks within a sampling time period. We assume that groups of multiple individuals will dive synchronously and so will be synchronous in producing echolocation clicks (Aguilar de Soto, 2006), and thus we model detection probabilities of groups to be the same as for individuals (but see Sec. IV).

\section{Line-transect $\mathrm{g}(0)$ estimation}

The probability that a beaked whale will be foraging and producing regular echolocation clicks at a given instant can be estimated as the proportion of time spent actively foraging (and clicking). This instantaneous probability could be a direct estimate of acoustic $g(0)$ for line-transect surveys if detections were limited to those beaked whales that are actively foraging at the instant the hydrophone passes (i.e., at the closest point of approach). In reality, however, localization using acoustic signals is harder than detection, and it is not always possible to accurately identify the point of closest approach. The problem of determining the instant of closest approach can be side-stepped and samples sizes can be increased if $g(0)$ is estimated for all detected beaked whales over a finite time window. Some of these detections will include animals ahead of the ship, which are foraging at the time they are detected but which stop foraging by the time of closest approach. Similarly, some of these detections will include animals that are not foraging at the time of closest approach but which start foraging and are detected acoustically after the hydrophone passes them. This situation is similar to the visual detection of animals at the surface using aerial surveys when they are intermittently available and are visible some distance ahead and/or behind the aircraft (McLaren, 1961; Barlow et al., 1988; Laake et al., 1997). From Eq. (5) in Laake et al. (1997), the probability of detecting an animal at zero perpendicular distance is given by

$$
g(0)=(E(a)+w) /(E(a)+E(u))
$$

where $E(a)=$ expected value of the time available to be detected (foraging time), $E(u)=$ expected time unavailable to be detected (time between foraging episodes), and $w$ $=$ time window $[w \ll E(u)]$ during which an animal could be detected.

If beaked whales can be acoustically detected at a range of $k$ (on the transect line, either in front of or behind the survey vessel), the time window, $w$, is equal to twice this range divided by the survey speed, $v$,

$$
w=2 * k / v .
$$

This approach assumes that survey speeds are greater than typical speeds of animal movement. Here we use means to represent expected values. An approximate variance for $g(0)$ associated with a finite time window is estimated using the delta method (Seber, 2002).

\section{Point-transect $\mathrm{g}(0)$ estimation}

Most point-transect estimates of animal density or abundance are based on short, discrete time periods that are separated from each other by sufficient time to reduce the temporal autocorrelation in the samples (Buckland et al., 2001). Samples that are very close together in time are not independent and provide redundant information. Use of long samples can result in a bias caused by movement of the animals into or out of detection range (Buckland, 2006). A common scenario for acoustic point-transect data is to record on a duty cycle, say 6 min each hour. Even if recording is continuous, discrete sub-samples separated in time can be used for point-transect analysis. Detections of the same individuals in multiple time periods does not bias density estimates, but if this is common, variance estimates need to account for this lack of independence between samples.

The instantaneous probability of acoustic detection can again be used as an estimate of acoustic $g(0)$ if it is applied to a single instant in time (e.g., the "snapshot" method of Buckland, 2006). For example, if a 6-min sample period is used, the instant of sampling could be defined as the midpoint of this period, and acoustic detections should be included only if the animals are actively foraging at this instant. The entire sampling period could be used to help determine whether clicking was likely occurring at the midpoint, but detections would be only included if this is true. In practice, however, it may not be possible to determine whether a distant group of acoustically detected beaked whales is clicking at any given instant because detection of the clicks will vary with the orientation of the animal, and reception will therefore fade in and out. This problem of determining clicking at a specific instant can be side-stepped and sample size can be increased by estimating $g(0)$ for the entire sample period. The same formula [Eq. (1)] is appropriate, but in this case $w$ is equal to the duration of the sample period.

\section{Robust estimates of uncertainty}

Multiple dives for one tag deployment cannot be considered as independent samples for making inference or estimating parameters to describe diving behavior. Successive dives by the same individual over a short period are likely to be more similar than dives made by different individuals or even dives made by the same individual several days apart. For estimating uncertainty in parameter estimates, we consider a single tag deployment to be the basic unit of sampling. In estimating the standard error of dive parameters within a sampling location, we treated the mean values for each individual as a sample. Similarly, individuals in one location are likely to have more similar diving behavior than would individuals in different locations. In estimating the standard error of dive parameters for all locations pooled, we treated the mean value for each location as a sample. Individual dives were treated as replicate samples only in 

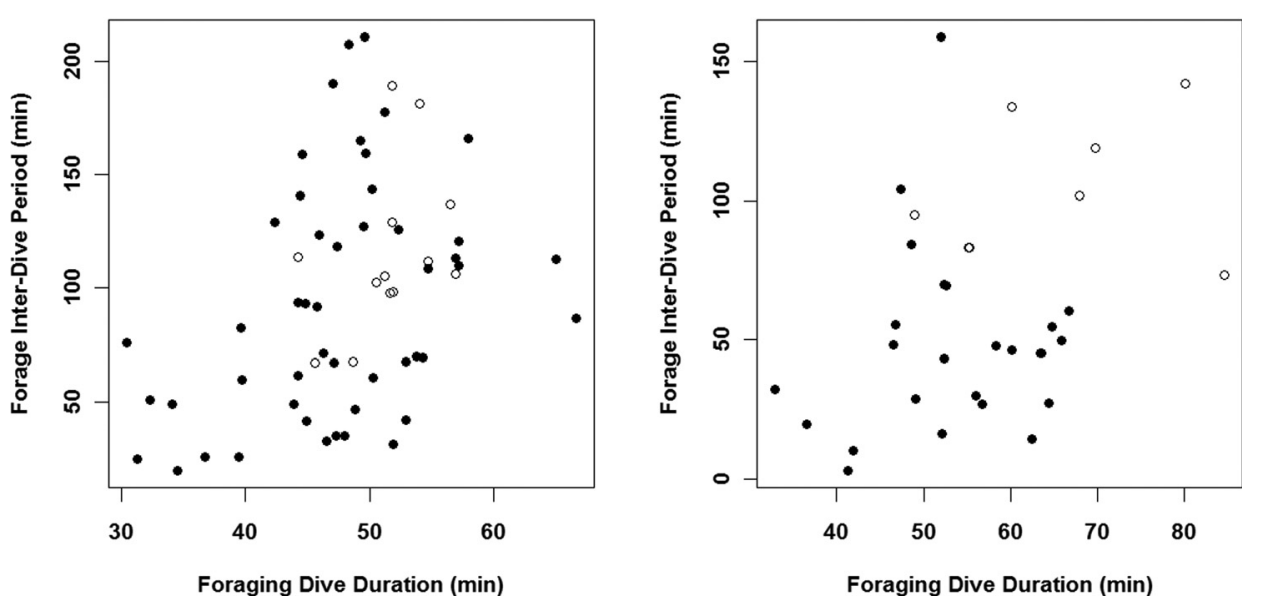

FIG. 2. Comparison of foraging dive durations and inter-dive intervals for the first foraging dive after tagging (open circles) and for all other foraging dives (closed circles) for Blainville's and Cuvier's beaked whales. Only DTAG data are included and foraging dives are identified based on the presence of echolocation clicks.

ANOVA that specifically included effects due to individual differences.

\section{RESULTS}

\section{A. Tagging studies}

Various types of tags that record dive behavior were deployed on a total of 16 Cuvier's beaked whales and 24 Blainville's beaked whales at various locations around the world (Table I). These tag data are from studies that were designed for other purposes. The species tagged and tagging locations were based on the availability of animals, calm seas, and tags and were not based on any statistical design. The only area where both species were tagged and where more than one type of tag was used is Hawaii. In analyses of behavioral differences, this lack of a factorial design prevents a clear separation of differences due to tag type from differences in tagging location.

All acoustic recording tags (DTAGs) showed the same pattern of acoustic behavior as had been noted in previous analyses (Tyack et al., 2006). Both species of beaked whales initiated echolocation only during their descent in a long, deep dive and continued making clicks until the end of the foraging part of these dives (Fig. 1). Like other authors (Johnson et al., 2004; Madsen et al., 2005), we infer that these long, deep dives with echolocation clicks are foraging dives.
These foraging dives were typically followed by a series of shorter, shallower dives with no echolocation clicks, but at times two foraging dives were made with little time between them (Fig. 1, left panel). Compared to other foraging dives, the time between the first and second foraging dives after tagging (Fig. 2) is significantly different (longer) for Blainville's beaked whale (Kolmogorov-Smirnov $(\mathrm{K} / \mathrm{S})$ test, $p=0.03$ ) and for Cuvier's beaked whale (K/S test, $p<0.001)$. The durations of the first foraging dives were also longer for both species (Fig. 2 ), but this difference was not significant (K/S test, $p=0.07$ and 0.13 , respectively). The first foraging dive and inter-dive interval after tagging were excluded in analyses presented in the remainder of this paper for all tag types to reduce potential bias caused by the immediate response of animals to tagging.

Foraging dives from TDR tags and satellite-TDR tags are identified based on a multiplicative product of dive depth and dive time (Fig. 3). This product provides better separation of the modes between foraging and non-foraging dives than either dive depth or dive time if considered separately. Based on data from acoustic recording DTAGs, all of the foraging dives (those with echolocation clicks) are correctly classified using depth $\times$ time criteria of $12500 \mathrm{~m}$-min for Blainville's beaked whale and $25000 \mathrm{~m}$-min for Cuvier's beaked whale. Applying these criteria clearly separated dive data from all types of tags and all locations into two modes, which we interpret as non-foraging and foraging dives
Blainville's beaked whale

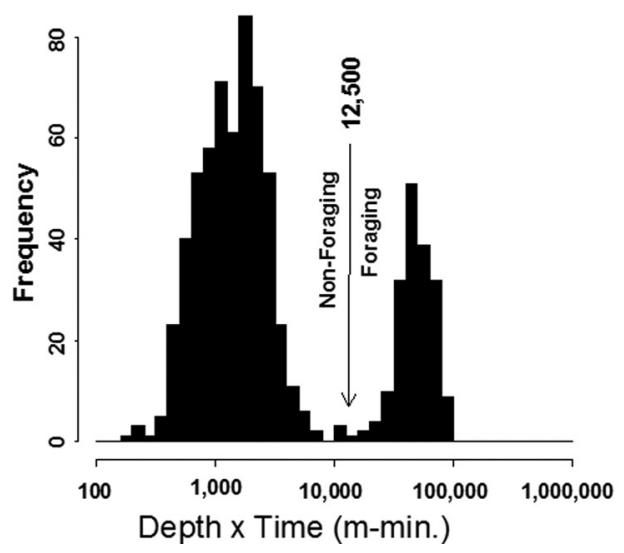

Cuvier's beaked whale

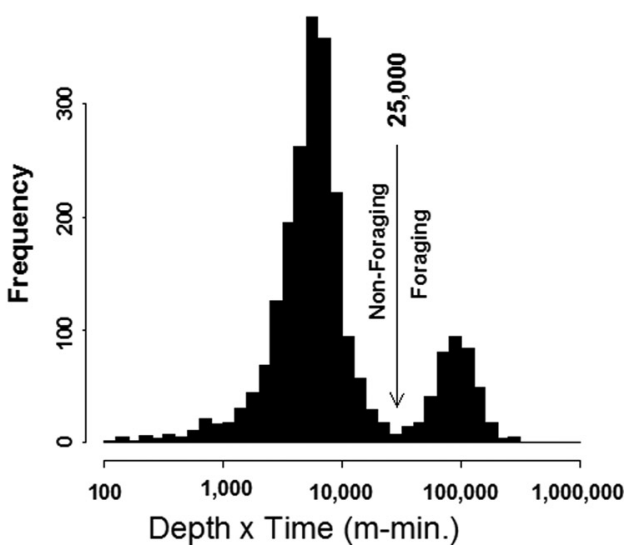

FIG. 3. Frequency distributions of dive depths multiplied by dive times showing the modal separation of foraging and non-foraging dives. Data include all tag types and locations. Values of $12500 \mathrm{~m}$-min for Blainville's beaked whale and $25000 \mathrm{~m}$-min for Cuvier's beaked whale distinguish all foraging dives (those with echolocation clicks) from all non-foraging dives for the acoustic-recording DTAG data. 
TABLE II. Average fraction of time spent in foraging dives and fraction of time actively foraging (producing regular echolocation clicks) for tagged beaked whales. Mean values for each location and tag type are the average of the means for each individual. Standard errors (in parentheses) are not available (N/A) if the number of tag deployments in a location is less than 3. Means and standard errors for all areas are calculated from the location/tag-type mean values. First foraging dives and inter-dive intervals after tagging are excluded. For DTAGs, the fraction of time actively foraging is measured directly based on the fraction of time clicking (both in bold). For other tag types, the fraction of foraging dives with active foraging is not estimated (N/E). For these tag types, the fraction of time actively foraging was estimated by multiplying the fraction of foraging dives with echolocation clicks (from DTAG data) by the fraction of total time in foraging dives.

\begin{tabular}{|c|c|c|c|c|c|}
\hline Species & Location & Tag-type & $\begin{array}{l}\text { Fraction of total } \\
\text { time in foraging dives }\end{array}$ & $\begin{array}{l}\text { Fraction of foraging } \\
\text { dive actively foraging }\end{array}$ & $\begin{array}{l}\text { Fraction of total } \\
\text { time actively foraging }\end{array}$ \\
\hline \multirow[t]{4}{*}{ Blainville's beaked whale } & Canary Islands & DTAG & $0.368(0.039)$ & $0.534(0.019)$ & $0.192(0.014)$ \\
\hline & Bahamas & DTAG & $0.339(0.019)$ & $0.571(0.036)$ & $0.206(0.011)$ \\
\hline & Hawaii & TDR & $0.332(0.025)$ & $\mathrm{N} / \mathrm{E}$ & $0.181(0.030)$ \\
\hline & All areas pooled & All & $0.346(0.011)$ & $0.545(0.017)$ & $.193(0.007)$ \\
\hline \multirow[t]{5}{*}{ Cuvier's beaked whale } & Ligurian Sea & DTAG & $0.569(0.041)$ & $0.588(0.019)$ & $0.345(0.037)$ \\
\hline & Hawaii & TDR & $0.441(0.025)$ & $\mathrm{N} / \mathrm{E}$ & $0.259(0.032)$ \\
\hline & Hawaii & SLTDR & 0.493 (N/A) & $\mathrm{N} / \mathrm{E}$ & 0.290 (N/A) \\
\hline & Southern California & SLTDR & $0.386(\mathrm{~N} / \mathrm{A})$ & $\mathrm{N} / \mathrm{E}$ & $0.227(\mathrm{~N} / \mathrm{A})$ \\
\hline & All areas pooled & All & $0.473(0.039)$ & $0.588(0.019)$ & $0.280(0.025)$ \\
\hline
\end{tabular}

(Fig. 3). Foraging dives are identified based on these criteria in the remainder of this paper. Within foraging dives, the time spent actually foraging is identified as that time when beaked whales are producing echolocation clicks (i.e., from the start to end of regular clicking). There are occasional breaks in clicking during this interval due to pauses or the production of buzzes in which the clicks are much weaker (Madsen et al., 2005), but these comprise a small portion of the total clicking time.

The fraction of time in foraging dives is estimated as the duration of each foraging dive divided by the sum of its duration plus the duration of the next interval between foraging dives. Using the above criteria to identify foraging dives, multivariate ANOVA identifies several factors that affect the duration of dives and inter-dive periods for foraging dives. For Blainville's beaked whale, the fraction of time in foraging dives is not significantly related to location $(p=0.78)$, tag type $(p=0.25)$, or individual $(p=0.06)$ but is significantly related to time-of-day $(p=0.007)$. For Cuvier's beaked whale the fraction of time in foraging dives is not significantly related to time-of-day or individual $(p=0.86)$ but is significantly related to location/tag type (both are confounded and cannot be considered separately) $(p=0.001)$.
The overall percentage of time in foraging dives is estimated for each individual by summing the duration of all their foraging dives and dividing by the total sampled time period (including only complete cycles of a foraging dive and subsequent inter-dive period). Mean values for each sample location are calculated as the average of values for individuals, and overall means are calculated as the average over all location means (Table II). These percentages are higher for Cuvier's beaked whales (51\%) than for Blainville's beaked whale (38\%), and this pattern is observed in all of the study areas (Table II).

The fraction of each foraging dive during which beaked whales are actively foraging (and producing echolocation clicks) can be estimated directly from acoustic recording tags (DTAG data) (Fig. 4). Analysis of covariance shows that this fraction is not significantly related to dive time or individual for either species (ANOVA F-statistic, $p>0.05$ ), and for Blainville's beaked whale (which were tagged with DTAGs in multiple locations) this fraction was not significantly related to tagging location (ANOVA F-statistic, $p=0.48$ ). When both species were pooled, the fraction of each foraging dive with clicking did not differ between species, with dive time, or among individuals (ANOVA F-statistic, $p>0.05$ ).
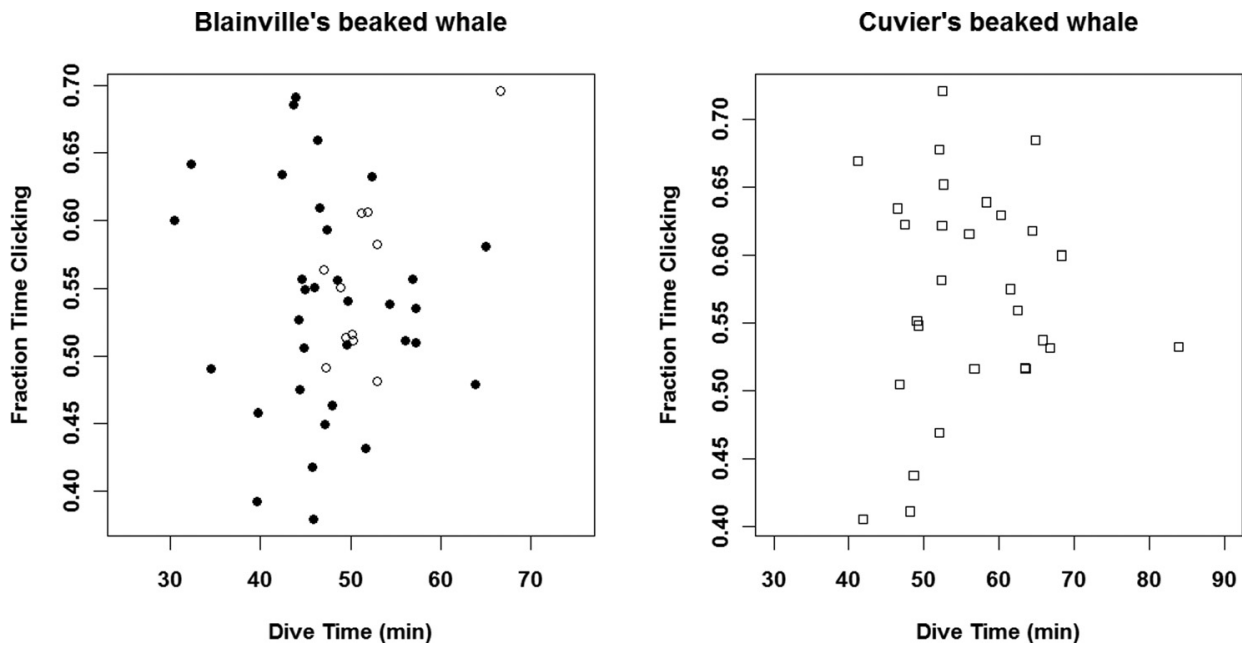

FIG. 4. Fraction of foraging dives during which beaked whales were producing echolocation clicks (hence, actively foraging) plotted as a function of foraging dive duration. Data are from DTAGs deployed in the Canary Islands (closed circles), the Bahamas (open circles), and in the Ligurian Sea (open squares). 
The mean fraction of time in all foraging dives with clicking is 0.542 (s.e. $=0.011$ ) for Blainville's beaked whales, 0.571 (s.e. $=0.015)$ for Cuvier's beaked whale, and 0.553 (s.e. $=0.009)$ for both species pooled. These species-specific values estimated directly from DTAG data are used to estimate the fraction of foraging dives with clicking for the other tag types, which did not record acoustic data.

The fractions of total time spent actively foraging and producing echolocation clicks are given in Table II for each species, tagging location, and tag type. These mean values are measured directly from DTAG data and are estimated for the other two types of tags (foraging dives are identified by a dive time/depth criteria and the portions of foraging dives with echolocation clicks is based on the mean values from DTAG data). Overall, Cuvier's beaked whale produced echolocation clicks for a greater fraction of time (28\%) than Blainville's beaked whale (19\%), and the same pattern is seen in all locations.

\section{B. Estimates of $g(0)$}

For both line- and point-transect acoustic surveys, the fractions of time spent actively foraging and echolocating are instantaneous estimates of $g(0)$. These instantaneous values for Blainville's beaked whale [mean $=0.19$, standard deviation (s.d.) $=0.01$, standard error (s.e.) $=0.007]$ and Cuvier's beaked whale (mean $=0.28$, s.d. $=0.05$, s.e. $=0.025)$ apply only to surveys that define acoustic detections based on an instant in time, such as the moment of closest approach in a line-transect survey or the mid-point of a sampling interval for point-transect surveys. Using this approach, acoustically detected beaked whales would not be used in abundance or density estimation unless they were producing echolocation clicks at these defined instants in time. If, instead, acoustic detections are made over some finite time window, estimates of $g(0)$ need to account for this.

For line-transect acoustic surveys using towed hydrophone arrays, beaked whales that are located directly under the transect line can be detected at some distance ahead or behind the ship. The time interval over which beaked whales can be detected depends on this distance and on the speed of the ship. The dependence of $g(0)$ on vessel speed and detection distance is illustrated in Fig. 5. Detection distance is modeled as a knife-edge function (all individuals are detected out to that distance and none at greater distance); however, the results would be similar using effective detection distance instead (the range out to which the number of vocalizing beaked whales that are undetected is equal to the number detected at greater range). We assume that animals are detected equally well ahead and behind the vessel. For a typical survey speed of $18 \mathrm{~km} \mathrm{hr}^{-1}$ and a typical horizontal detection distance of $2 \mathrm{~km}, g(0)$ would be 0.28 (s.e. $=0.01$ ) for Blainville's beaked whale and 0.39 (s.e. $=0.03$ ) for Cuvier's beaked whale. Trackline detection probabilities for Cuvier's beaked whale are higher than for Blainville's beaked whale (Fig. 5) largely because that species spends a greater fraction of its time actively foraging.

For point-transect surveys of Blainville's and Cuvier's beaked whale, the probabilities of detecting a whale directly
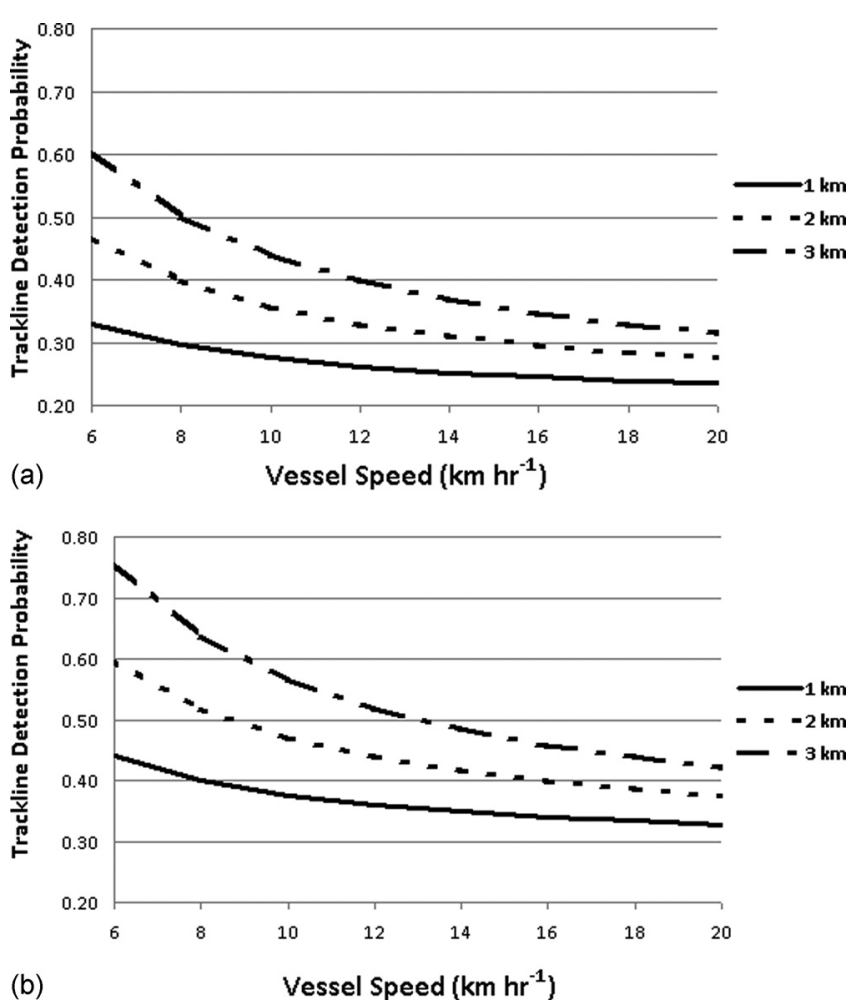

FIG. 5. Trackline detection probabilities $(g(0))$ for acoustic line-transect surveys of Blainville's beaked whale (top) and Cuvier's beaked whale (bottom) as functions of vessel speed and effective detection distance $(1-3 \mathrm{~km})$. Values are based on unweighted averages of all sampled areas and, thus, are appropriate to apply to a novel study area.

above a bottom-mounted hydrophone or directly below a floating hydrophone are illustrated in Fig. 6 as functions of the time window over which detections are tallied. For point-transect surveys, the sampling window needs to be short to avoid bias caused by animal movement (Buckland, 2006), so a 10-min window was chosen as a maximum in this figure. For a 6-min time window, the detection probabilities are 0.22 (s.e. $=0.008)$ and 0.33 (s.e. $=0.029$ ) for Blainville's and Cuvier's beaked whale (respectively).

\section{DISCUSSION}

\section{A. Diving and echolocation behavior}

The diving and echolocation behaviors of Blainville's and Cuvier's beaked whales are, in many ways, ideal for estimation of their abundance and density using acoustic survey methods. Their diving patterns are very stereotyped, with long foraging dives followed by a series of surfacings and shorter, non-foraging dives (Baird et al., 2006; Tyack et al., 2006). Echolocation signals are commonly produced only during the portion of the long foraging dives when they are deeper than several hundred meters. Some significant geographic and diurnal differences were found in their diving behavior (Table I), but the magnitudes of these differences are relatively small. Indeed, the proportion of time during which echolocation clicks were produced in foraging dives did not differ among locations or even between species, indicating that this component of their diving behavior is extremely stereotyped. 


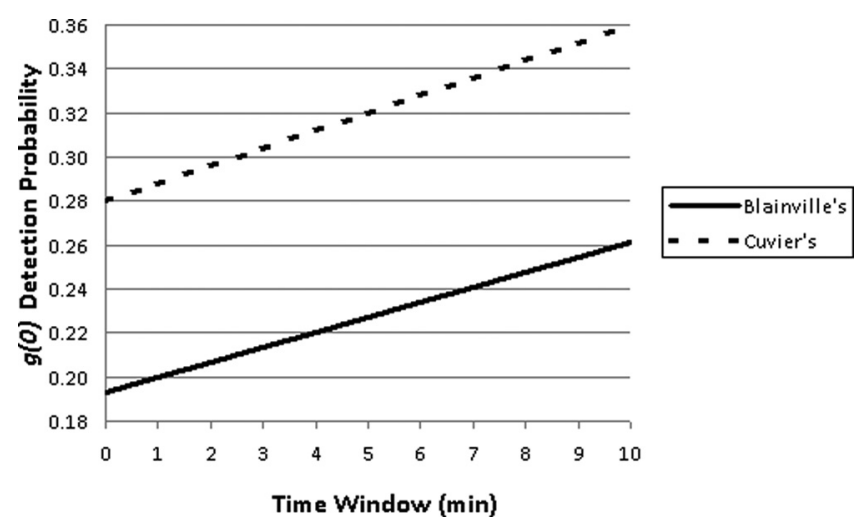

FIG. 6. Detection probabilities at zero horizontal distance from a hydrophone $[g(0)]$ for acoustic point-transect surveys of Blainville's and Cuvier's beaked whales as functions the time window over which detections are counted.

Although diving and foraging behavior is very stereotyped in beaked whales, we did find some significant differences in the fraction of time spent in foraging dives. The most notable difference was between species, with Cuvier's beaked whales spending more time in foraging dives than Blainville's beaked whales. For Blainville's beaked whale we also found significant diurnal differences (see also Baird et al., 2008, whose analysis included a subset of our data), and for Cuvier's beaked whale we found significant difference with tag type/location. Differences among individuals were not significant for either species (using complete dive cycles as replicates). However, we expect that with larger sample sizes in more regions, we would find significant differences among individuals and among locations for both species. Although these differences appear to be small in our samples, we do not believe that beaked whales are all identical in their behavior. For this reason, we think that in making robust estimates of parameter uncertainty, it is more reasonable to treat individuals as replicates when generalizing results to a location and to treat locations as replicates when generalizing our results to unsampled locations. If diurnal differences in diving behavior are verified in future studies and if acoustic surveys are conducted at night, consideration should be given to estimating $g(0)$ values that are specific to time-of-day.

The generality of our results is dependent on the assumption that tagged whale behavior is the same as that of beaked whales in the general population. We did not find any significant difference in the duration of the first foraging dive after tagging compared to all other foraging dives, which is the same result obtained by Tyack et al. (2006) using a subset of the same data. However, we did find that the first period between foraging dives after suction-cup tagging with DTAGs was significantly different (longer) than that for subsequent dives for both Blainville's and Cuvier's beaked whales. We consider this as likely evidence that tagging affects behavior of beaked whales immediately after tagging. Of course, it is also possible that this is an artifact of situations under which tagging is possible. If beaked whales are spending more time at the surface, they might be easier to tag and co-incidentally might be more likely to have longer inter-dive periods on subsequent surfacings. Also, our inference that tagging affects behavior immediately after tagging is based only on DTAG data, and a larger sample size is needed to investigate whether other tag types affect behavior in a similar way. Nonetheless, we consider it prudent to exclude the first foraging diving and first interdive period after tagging when making inference about beaked whale behavior. Additional studies are needed to determine whether tagging might have other, longer-term effects on beaked whale behavior. Longer-duration tags, such as suction-cup TDR tags and satellite-TDR tags could be used to examine how long any tagging effect might last. A better approach might be to monitor behavior prior to tagging using a completely passive method, such as an array of hydrophones.

To avoid biased estimates due to unnatural behavior, we did not use behavioral data collected during acoustic playback experiments using simulated Navy sonar. It is possible that our TDR- and SLTDR-tagged animals were exposed to actual Navy sonar during the period when we were monitoring their behavior. This is especially likely for the SLTDRtagged Cuvier's beaked whales that were tagged on the SCORE Naval Range off Southern California, where sonar exercises are common. We are assuming that "normal" behavior for beaked whales now includes occasional changes in diving habit in response to the human-caused perturbations that are common in each sampled area.

\section{B. $g(0)$ estimates}

The estimates of $g(0)$ for an instant in time are much less than 1.0, with values for Blainville's beaked whale being less than those for Cuvier's beaked whale. In general, Blainville's beaked whales produce echolocation clicks approximately $18-21 \%$ of the time and Cuvier's beaked whales produce echolocation clicks approximately 23-35\% of the time (Table II). Analytically, these instantaneous estimates of $g(0)$ are, by far, the most straightforward to apply. The same values can be used for either point- or line-transect surveys if they are applied to an appropriate, pre-defined point in time (say the middle of a monitoring period for a point-transect survey or the time when a beaked whale passes abeam in a line-transect survey). Applying $g(0)$ values over some time window for a point-transect survey requires either the assumption that beaked whales do not travel appreciable distances over that time period or requires additional information on movement patterns and a complicated model to account for that movement. Similarly, applying $g(0)$ values over some time window associated with the movement of a survey vessel in a line-transect survey also requires additional information on the range at which beaked whales can be detected ahead or behind the vessel.

All of the estimates of $g(0)$ presented here depend on the assumption that beaked whales are always detected when they are producing regular echolocation clicks directly under a near-surface hydrophone or directly over a bottommounted hydrophone (i.e., at zero horizontal distance). Although empirical evidence and propagation modeling provide some support for this assumption, it may not be valid at 
all times or in all situations. The empirical data and propagation models are based on quiet ocean conditions, and vessel noise and other sources of ambient noise are likely to reduce the probability of detecting beaked whale clicks (Soto et al., 2006). Tagging data have shown that Cuvier's beaked whale dives can exceed $2 \mathrm{~km}$ depth (Schorr et al., 2011), and the likelihood of detecting beaked whale echolocation clicks at the surface are likely to decrease with the depth of the whale. Beaked whales begin clicking when they are still descending, and a downwardly directed echolocation click is less likely to be detected on a near-surface hydrophone than on a bottom-mounted hydrophone. In general, we expect that our assumption that all beaked whales will be detected at zero horizontal distance will not always be true and that our $g(0)$ estimates are therefore biased upward, which will lead to an underestimate of beaked whale abundance. In the future, empirical data may allow direct estimation of the fraction of foraging beaked whales that might be missed at zero horizontal distance. Our $g(0)$ component based on the probability of clicking could then be multiplied by the $g(0)$ component based on the probability of detection given clicking to estimate an overall $g(0)$ that includes both.

We have also assumed that the probability of detection does not depend on group size and that a group of closely associated beaked whales forages synchronously and so produces echolocation clicks over the same interval as would a single animal (Aguilar de Soto, 2006). Although beaked whale groups typically surface and dive synchronously (within a minute or so), little is known about their underwater behavior. If clicking behavior is not strictly synchronous, then the probability of at least one individual in a group producing echolocation clicks will be higher than the probability estimated here for a solitary individual. DTAG data, such as that used here, could be analyzed in more detail to extract the echolocation behavior of other members within a group.

\section{RECOMMENDATIONS}

We recommend that the instantaneous (snapshot) approach to estimating detection probabilities $[g(0)]$ should be used whenever possible in applying point- or line-transect surveys to beaked whales. Approaches that depend on using a finite time window for detections require additional information that is currently unavailable and difficult to obtain. The snapshot method is based on fewer assumptions and is analytically simple to apply. There may, however, be situations when the instantaneous approaches will not work for practical, logistical reasons.

For point-transect surveys, it is easy to define a sampling instant (say halfway through a sampling period), and only tally detections if beaked whales are producing echolocation clicks within a short time window around that instant. Given the ratio of $g(0)$ values (Fig. 6), a 6-min sampling period will result in a sample size of "detected" whales that is only about 11-17\% larger than for the sampling instant method. This increase in sample size is not sufficient to justify the use of the less robust time-window method. One practical limitation, however, is that not all echolocation clicks are detected. Clicks may be detected intermittently, depending on the orientation of the animals and the beam pattern of their echolocation clicks (Marques et al., 2009). This intermittent reception is not likely to be a large problem in the near vicinity of a sampling point because a close whale that is clicking continuously is likely to produce detectable echolocation clicks within a few minutes both before and after a defined sampling instant. However, the same is not necessarily true for more distant whales. Only a few echolocation clicks may be detectable from a distant whale during a sampling period and it may be impossible to determine whether the whale is clicking at the defined sampling instant. A key component of distance sampling with points is the ability to estimate the range from the detector to the detected whales, so we assume that distance can be estimated. Clicks are received more consistently from closer whales, so it is easier to determine whether a whale is clicking at a given instant by eliminating detections of distant beaked whales. This distance truncation, however, is likely to result in a much greater reduction in the sample size of detected whales than the reduction due to sampling an instant in time instead of a time window. Therefore, point sampling based on detections accumulated over a short period of time may still be a useful technique. Additional empirical studies are required to determine if the preferred "snapshot" approach is feasible.

Similarly, it is easy to define an instant in time to apply our instantaneous $g(0)$ estimates to line-transect sampling. For example, samples could be limited to beaked whales that are producing echolocation clicks when the ship is at its closest point of approach. The point-of-closest-approach is a convenient instant to use because it is also the time period when echolocation clicks should be most consistently received. However, when beaked whales are at greater distances from the transect line and their echolocation clicks are received very intermittently, it may again be difficult to determine whether beaked whales are producing echolocation clicks at the precise time of closest approach. Again, horizontal detection distance (in this case, the horizontal distance at closest approach) can be used to eliminate distant detections and improve the ability to unambiguously determine whether detected beaked whales are producing echolocation clicks at a given instant. However, this criterion might also limit sample sizes. However, for line-transect surveys, unless beaked whale echolocation signals are detected near the time of closest approach, it might not be possible to estimate detection distance using the convergence of bearing angles (Barlow and Taylor, 2005), so the time-instant criterion might not limit sample sizes much beyond the limitation already imposed by the need to estimate horizontal detection distance. Again, empirical data are needed to evaluate the feasibility of using the "snapshot" method for line-transect surveys.

The estimation of beaked whale abundance using acoustic detection and distance sampling methods is still in its infancy. To date, acoustic line-transect methods have not been used to estimate beaked whale abundance in any peer-reviewed publication, and point-transect methods have only been used in a very limited context of a dense array of 
bottom hydrophones. In part, this is because of a lack of relevant estimates of acoustic detection probabilities, $g(0)$. We hope that the estimates of $g(0)$ presented here based on the foraging patterns of tagged beaked whales will fill a gap and promote the broader use of acoustic tools to estimate beaked whale abundance. We anticipate that future research will be able to examine some of the assumptions we made and to improve upon these estimates. Some specific research recommendations follow.

(1) Additional studies of the effects of tagging on beaked whale behavior by using multiple types of tags in a single location and by using longer-duration tags.

(2) Empirical studies of the probability of detecting beaked whales at zero horizontal distance, especially for nearsurface hydrophones.

(3) Empirical studies to determine how the probability of acoustic detection of beaked whales changes with horizontal range and observation interval for near-surface hydrophones.

(4) Additional studies of the diving and acoustic behavior of groups of beaked whales, including more study locations and more beaked whale species.

(5) Additional analysis of existing DTAG and hydrophone array data to examine the synchrony of echolocation behavior in groups of beaked whales.

(6) More applications of distance sampling methods to estimate the density and abundance of beaked whales and to determine the feasibility of the snapshot approach applied to $g(0)$ for line- and point-transect surveys.

\section{ACKNOWLEDGMENTS}

Tagging in Hawaii was conducted under Scientific Research Permit No. 731, 774, and 540-1811 issued by the U.S. National Marine Fisheries Service (NMFS). Dtagging in European waters was conducted under US NMFS permits 981-1578-02 and 981-1707-00 and annual permits from the Canary Islands Government to the University of La Laguna. Tagging in the Bahamas was conducted under US NMFS permits issued to John Boreman (Permit No. 1121-1900) and to Peter Tyack (Permit No. 981-1578), and issued by the Government of the Bahamas to the Bahamas Marine Mammal Research Organisation (Bahamas permit No. 01/ 09) and Ian Boyd (Bahamas permit Nos. 02/07 and 02/08). The Dtagging was approved by the WHOI and BMMRO Institutional Animal Care and Use Committees and the Animal Welfare and Ethics Committee of the University of St Andrews. Funding for this work was provided by the U.S. Navy (N45 and ONR), the U.S. Strategic Environmental Research and Development Program (www.serdp.org), the U.S. Chief of Naval Operations Submarine Warfare Division, the U.S. National Oceanic and Atmospheric Administration (National Marine Fisheries Service, Office of Science and Technology) (http://www.st.nmfs.noaa.gov/), U.S. National Oceanic and Atmospheric Administration Ocean Acoustics Program (http://www.nmfs.noaa.gov/pr/ acoustics/), NMFS's Southwest Fisheries Science Center, NMFS's Pacific Islands Fisheries Science Center, the M.R. and Evelyn Hudson Foundation, the Wild Whale Research
Foundation, the Joint Industry Program on Sound, National Ocean Partnership Program, the Packard Foundation, the Canary Islands Government, the Spanish Ministries of Defense and Environment, the project LIFE-Indemares, the Cabildo Insular de El Hierro, and the Marine Life Program of the International Association of Oil and Gas Producers (www.soundandmarinelife.org). N.A.S. is currently funded by a Marie Curie fellowship from the 7th EU Frame Program. This manuscript was improved by helpful reviews by Jeffrey E. Moore, William F. Perrin, and Jeffrey L. Laake. The authors gratefully acknowledge the invaluable support of field personnel in all tagging locations, especially Patricia Arranz, Alex Bocconcelli, Andrea Fais, Erin Falcone, Jeff Foster, Leigh Hickmott, Allan Ligon, Peter T. Madsen, Jacobo Marrero, Lucia Martin, Dan McSweeney, and Daniel Webster. We thank Dave Moretti and his team from the Marine Mammal Monitoring on Ranges, and the support from the Navy's Southern California Offshore Range.

Aguilar de Soto, N. (2006). "Acoustic and diving behaviour of short-finned pilot whales (Globicephala macrorhynchus) and Blainville's beaked whales (Mesoplodon densirostris) in the Canary Islands. Implications on the effects of man-made noise and boat collisions," Ph.D. Dissertation, Department of Animal Biology, University of La Laguna, Tenerife, Canary Islands.

Aguilar de Soto, N., Johnson., M., Tyack., P., Arranz, P., Revelli, E., Marrero, J., Fais, A., and Madsen, P. (2012). "No shallow talk: deep social communication of Blainville's beaked whales," Marine Mammal Sci. 18(2), E75-E92.

Andrews, R. D., Pitman, R. L., and Balance, L. T. (2008). "Satellite tracking reveals distinct movement patterns for Type $\mathrm{B}$ and Type $\mathrm{C}$ killer whales in the southern Ross Sea, Antarctica," Polar Biol. 31, 1461-1468.

Arranz, P., Aguilar Soto, N., Madsen, P. T., Brito, A., Bordes, F., and Johnson, M. (2011). "Following a foraging fish-finder: Fine-scale habitat use of deep-diving Blainville's beaked whales revealed by echolocation," PLoS ONE 6(12), e28353.

Baird, R. W., Webster, D. L., McSweeney, D. J., Ligon, A. D., Schorr, G. S., and Barlow, J. (2006). "Diving behaviour and ecology of Cuvier's (Ziphius cavirostris) and Blainville s beaked whales (Mesoplodon densirostris) in Hawai'i," Can. J. Zool. 84, 1120-1128.

Baird, R. W., Webster, D. L., Schorr, G. S., Mcsweeney, D. J., and Barlow, J. (2008). "Diel variation in beaked whale diving behavior," Marine Mammal Sci. 24, 630-642.

Barlow, J., Ferguson, M., Perrin, W. F., Ballance, L. T., Gerrodette, T., Joyce, G., MacLeod, C. D., Mullin, K., Palka, D. L., and Waring, G. (2006). "Abundance and density of beaked and bottlenose whales (family ziphiidae),” J. Cetacean Res. Manage. 7, 263-270.

Barlow, J., Oliver, C., Jackson, T. D., and Taylor, B. L. (1988). "Harbor porpoise (Phocoena phocoena) abundance estimation in California, Oregon and Washington: II. Aerial surveys," Fish. Bull. 86, 433-444.

Barlow, J., and Taylor, B. L. (2005). "Estimates of sperm whale abundance in the northeastern temperate Pacific from a combined acoustic and visual survey," Marine Mammal Sci. 21, 429-445.

Baumann-Pickering, S., Wiggins, S. M., Roth, E. H., Roch, M. A., Schnitzler, H.-U., and Hildebrand, J. A. (2010). "Echolocation signals of a beaked whale at Palmyra Atoll," J. Acoust. Soc. Am. 127, 3790-3799.

Buckland, S. T. (2006). "Point transect surveys for songbirds: Robust methodologies," Auk 123, 345-357.

Buckland, S. T., Anderson, D. R., Burnham, K. P., Laake, J. L., Borchers, D. L., and Thomas, L. (2001). Introduction to Distance Sampling: Estimating Abundance of Biological Populations (Oxford University Press, Oxford).

Dawson, S. M., Barlow, J., and Ljungblad, D. (1998). "Sounds recorded from Baird's beaked whale, Berardius bairdi," Marine Mammal Sci. 14, 335-344.

Gillespie, D., Dunn, C., Gordon, J., Claridge, D., Embling, C., and Boyd, I. (2009). "Field recordings of Gervais' beaked whales Mesoplodon europaeus from the Bahamas," J. Acoust. Soc. Am. 125, 3428-3433. 
Hooker, S. K., and Whitehead, H. (2002). "Click characteristics of northern bottlenose whales (Hyperoodon ampullatus)," Marine Mammal Sci. 18, 69-80.

Johnson, M., Hickmott, L. S., Aguilar Soto, N., and Madsen, P. T. (2008). "Echolocation behaviour adapted to prey in foraging Blainville's beaked whale (Mesoplodon densirostris)," Proc. R. Soc. London, Ser. B 275, 133-139.

Johnson, M., Madsen, P. T., Zimmer, W. M. X., de Soto, N. A., and Tyack, P. L. (2004). "Beaked whales echolocate on prey," Proc. R. Soc. London, Ser. B 271, S383-S386.

Johnson, M., Madsen, P. T., Zimmer, W. M. X., de Soto, N. A., and Tyack, P. L. (2006). "Foraging Blainville's beaked whales (Mesoplodon densirostris) produce distinct click types matched to different phases of echolocation,” J. Exp. Biol. 209, 5038-5050.

Johnson, M. P., and Tyack, P. L. (2003). "A digital acoustic recording tag for measuring the response of wild marine mammals to sound," IEEE J. Ocean. Eng. 28, 3-12.

Küsel, E. T., Mellinger, D. K., Thomas, L., Marques, T. A., Moretti, D. J., and Ward, J. (2011). "Cetacean population density estimation from single fixed sensors using passive acoustics," J. Acoust. Soc. Am. 129, 3610-3622.

Laake, J. L., Calambokidis, J., Osmek, S. D., and Rugh, D. J. (1997). "Probability of detecting harbor porpoise from aerial surveys: Estimating $g(0)$," J. Wildl. Manage. 61(6), 63-75.

MacLeod, C., Perrin, W. F., Pitman, R., Barlow, J., Ballance, L. T., D’Amico, A., Gerrodette, T., Joyce, G., Mullin, K. D., Palka, D. L., and Waring, G. T. (2006). "Known and inferred distributions of beaked whale species (Cetacean: Ziphiidae),” J. Cetacean Res. Manage. 7, 271-286.

Madsen, P. T., Johnson, M., Aguilar de Soto, N., Zimmer, W. M. X., and Tyack, P. (2005). "Biosonar performance of foraging beaked whales (Mesoplodon densirostris)," J. Exp. Biol. 208, 181-194.

Marques, T. A., Thomas, L., Martin, S. W., Mellinger, D. K., Wards, J. A., Moretti, D. J., Harris, D., and Tyack, P. L. (2013). "Estimating animal population density using passive acoustics," Biol. Rev. 88, 287-309.

Marques, T. A., Thomas, L., Ward, J., DiMarzio, N., and Tyack, P. I. (2009) "Estimating cetacean population density using fixed passive acoustic sensors: An example with Blainville's beaked whales," J. Acoust. Soc. Am. 125, 1982-1994.

McLaren, I. A. (1961) "Methods of determining the numbers and availability of ringed seals in the eastern Canadian Arctic," Arctic 14, 161-175.
Moretti, D., DiMarzio, N., Morrissey, R., Ward, J., and Jarvis, S. (2006). "Estimating the density of Blainville's beaked whale (Mesoplodon densirostris) in the Tongue of the Ocean (TOTO) using passive acoustics," in Proceedings of the Oceans'06 MTS/IEEE-Boston, Boston, MA.

Moretti, D., Marques, T., Thomas, L., DiMarzio, N., Dilley, A., Morrissey, R., McCarthy, E., Ward, J., and Jarvis, S. (2010). "A dive counting density estimation method for Blainville's beaked whale (Mesoplodon densirostris) using a bottom-mounted hydrophone field as applied to a midfrequency active (MFA) sonar operation," Appl. Acoust.71, 1036-1042.

Schorr, G. S., Falcone, E. A., Morretti, D. J., McCarthy, E. M., Hanson, M. B., and Andrews, R. D. (2011). "The bar is really noisy, but the food must be good: High site fidelity and dive behavior of Cuvier's beaked whales (Ziphius cavirostris) on an anti-submarine warfare range," in Abstracts of the 19th Biennial Conference on the Biology of Marine Mammals, Tampa, FL, p. 265.

Seber, G. A. F. (2002). The Estimation of Animal Abundance and Related Parameters (Blackburn, Caldwell, NJ), pp. 7-9.

Soto, N. A., Johnson, M., Madsen, P. T., Tyack, P. L., Bocconcelli, A., and Borsani, J. F. (2006). "Does intense ship noise disrupt foraging in deepdiving Cuvier's beaked whales (Ziphius cavirostris)," Marine Mammal Sci. 22, 690-699.

Tyack, P. L., Johnson, M., Soto, N. A., Sturlese, A., and Madsen, P. T. (2006). "Extreme diving behaviour of beaked whales," J. Exp. Biol. 209, 4238-4253.

Tyack, P. L., Zimmer, W. M. X., Moretti, D., Southall, B. L., Claridge, D. E., Durban, J. W., Clark, C. W., D'Amico, A., DiMarzio, N., Jarvis, S., McCarthy, E., Morrissey, R., Ward, J., and Boyd, I. L. (2011). "Beaked whales respond to simulated and actual navy sonar," PLoS ONE 6(3), e17009.

Ward, J. A., Thomas, L., Jarvis, S., DiMarzio, N., Moretti, D., Marques, T. A., Dunn, C., Claridge, D., Hartvig, E., and Tyack, P. (2012). "Passive acoustic density estimation of sperm whales in the Tongue of the Ocean, Bahamas," Marine Mammal Sci. 28, E444-E455.

Zimmer, W. M. X. (2011). Passive Acoustic Monitoring of Cetaceans (Cambridge University Press, Cambridge), Chap. 6, pp. 198-236.

Zimmer, W. M., Harwood, J., Tyack, P. L., Johnson, M. P., and Madsen, P. T. (2008). "Passive acoustic detection of deep diving beaked whales," J. Acoust. Soc. Am. 124, 2823-2832.

Zimmer, W. M. X., Johnson, M. P., Madsen, P. T., and Tyack, P. L. (2005). "Echolocation clicks of free-ranging Cuvier's beaked whales (Ziphius cavirostris)," J. Acoust. Soc. Am. 117, 3919-3927. 